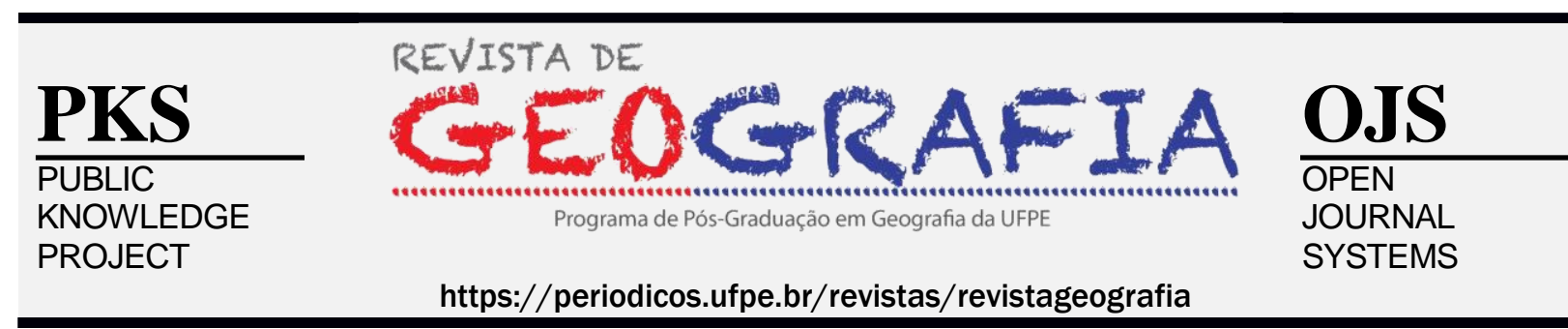

\title{
O CONCEITO DE CAMPONÊS NA ANÁLISE DOS SUJEITOS DA PRÁXIS PEDAGÓGICA
}

\author{
Celmara Coelho de Amorim ${ }^{1}$, Raimunda Áurea Dias de Sousa ${ }^{2}$
}

${ }^{1}$ Geógrafa pela Universidade de Pernambuco, Campus Petrolina, e professora da rede pública, Petrolina, Pernambuco, Brasil. E-mail: celmaramorim@hotmail.com

${ }^{2}$ Professora Adjunta da Universidade de Pernambuco, Campus Petrolina, e do Programa de Pós-Graduação em Formação de Professores e Práticas Interdisciplinares, Petrolina, Pernambuco, Brasil. E-mail: aurea.souza@upe.br

\begin{abstract}
RESUMO
O processo de ensino, em sua estrutura e funcionamento, só se caracteriza como práxis, no momento em que teoria e prática se determinam mutuamente, produzindo na relação com o objeto-sujeito desse processo - o aluno e o professor. Eles são sujeitos na medida em que constroem a história num contexto socialmente definidos e são objetos da história quando sofrem sua influência. Assim, o objetivo deste trabalho é compreender como os sujeitos da práxis pedagógica conceituam o camponês num momento em que há expansão do capitalismo no campo, justificado na necessidade da modernização da agricultura, que enxerga valores estritamente mercadológicos, ao tempo que desconsidera os valores da família camponesa, que lá se encontra. Desse modo, os conceitos construídos em sala de aula, especialmente, sobre o campo, dependem de diversos fatores, dentre eles, a postura do professor que pode sinalizar ou não no entendimento do fato social para além da aparência.

Palavras-chave: camponês; sujeito; sala de aula.
\end{abstract}

\section{THE CONCEPT OF PEASANT IN ANALYZING THE SUBJECT OF PEDAGOGICAL PRAXIS}

\begin{abstract}
The teaching process in its structure and functioning can only be characterized as praxis, in the moment that theory and practice determine each other, producing in relation with the object-subject of this process: student and teacher. They are subjected to the extent that build the story in a socially defined context, and are objects of this story when they suffer this influence. Thus, the aim of this paper is to understand how the subject of pedagogical Praxis conceptualizes the peasant at a time when there is an expansion of capitalism in the rural areas, which is justified as a need for modernization of Agriculture who strictly sees market values and disregards the values of peasant family that existing there. Thereby, the concepts constructed in the classroom, especially those regarding the field depend on several factors, including the teacher's posture that can signal, or not the understanding the social fact beyond the appearance.
\end{abstract}

Keywords: Peasant; Subject; Classroom. 


\section{INTRODUÇÃO}

As transformações pelas quais passa o campo na atualidade, centrado na modernização da agricultura por meio do agronegócio, cuja produção se volta completamente para o mercado externo, tornou pertinente entender, particularmente, em sala de aula, a utilização do conceito de camponês para a compreensão da realidade agrária, devido a sua história e de seu conteúdo sociopolítico e cultural que não desaparecem.

A questão agrária é tratada nos livros didáticos de Geografia no sentido do agrícola, que significa produção e produtividade em detrimento do agrário, que procura entender que o problema do campo está centrado na estrutura fundiária concentrada e não na produtividade. Nesse sentido, é imprescindível que o docente não seja apenas um transmissor de conteúdos de livros didáticos descontextualizados da prática, mas que tenha capacidade de reelaborar esses conteúdos a partir da realidade agrícola em que Petrolina-PE encontra inserida. O referido Município, em que foi desenvolvida a pesquisa, localiza-se no Sertão pernambucano e, por ser banhado pelo rio São Francisco, possibilitou a criação de políticas públicas voltadas para a implantação e concretização da agricultura irrigada. Essa, imprimiu uma nova forma de uso da terra com objetivos empresariais em detrimento da agricultura camponesa, cuja produção se volta completamente para atender aos interesses das famílias.

Com essa realidade presente no campo petrolinense em que há uma diferença gritante entre agricultura irrigada empresarial e agricultura camponesa, há transmissão descontextualizada de conteúdos em sala de aula sem uma ação teórico-prática que conduza os alunos a repensarem suas posturas em torno do campo. Ao optar pela transmissão, a ação docente não contribuirá para formação humana dele próprio e nem tão pouco dos alunos; portanto, não realizará a práxis já que ela trata-se de uma atividade humana e pressupõe a idealização consciente do sujeito que se propõe a intervir, a transformar a realidade.

Partindo da problemática: Por que o conceito de camponês passa despercebido pelos sujeitos da práxis pedagógica, especialmente, em Petrolina num momento em que há continuamente a expansão do capitalismo no campo? A necessidade de discutir a problemática proposta envolve sobremodo a reflexão crítica do modelo agrícola implantado no Município nos últimos anos. Desse modo, a dimensão histórica dialética é a garantia da 
leitura processual da dinâmica dos movimentos internos inscritos na totalidade das relações sociais mundiais.

Para alcançar o objetivo proposto, a metodologia da pesquisa foi estruturada em torno de três eixos de operacionalização: a organização de uma pesquisa bibliográfica; a realização de trabalho de campo com estudantes (100), professores da Educação Básica (10) em escolas do espaço urbano e rural em Petrolina-PE e, camponeses (03) para construção de um banco de dados estatísticos vinculados à elaboração de gráficos; a realização de pesquisa em livros didáticos de editoras diferentes (04); por fim, a apresentação dos dados da pesquisa em periódicos de alcance nacional e internacional. Para os referidos eixos, foram desenvolvidas práticas de campo que se definiram em análise quantitativa/qualitativa por meio da aplicação de questionários e do levantamento estatístico nas escolas, para perceber como os professores abordam o conteúdo - questão agrária; como também no resgate de experiências de vida e de trabalho a partir de instrumentos qualitativos como entrevista, depoimentos e consultas a documentos concernentes à análise do conceito de camponês nos livros didáticos.

\title{
O conceito de camponês pela análise dos/as professores/as de escolas do ensino fundamental
}

No texto de Souza Neto (1996) “A geografia enquanto ciência da cabra cega”, o autor faz uma comparação da geografia escolar com a brincadeira infantil denominada de cabra cega. Segundo ele:

\begin{abstract}
A geografia nos faz, sim, de cabras cegas. Esconde, no turbilhão de coisas que mostra a nossa espacialidade totalizada. Parcializa o que é global e delimita o que não pode ser limitado, quando se busca a compreensão do todo. E nos faz rodopiar tontos, com mil informações que não dizem respeito ao nosso viver concreto. Desta forma, esconde justamente quando parece ter mostrado. (SOUSA NETO, 1996, p.7)
\end{abstract}

O autor ilustra que é essa a Geografia que se encontra nos livros didáticos, nas práxis dos professores e se concretiza na aprendizagem dos alunos, evidenciando uma sociedade em que a escola, por meio do ensino sem análise crítica, contribui para a reprodução do capital, já que o grande objetivo desse sistema é tornar sujeitos cegos e tontos diante das mazelas da sociedade, e o aparelho ideal é a educação escolar. Como diz Mészáros (2008): 
A educação institucionalizada, especialmente nos últimos 150 anos, serviu - no seu lado - ao propósito de não só fornecer os conhecimentos e o pessoal necessário à máquina produtiva em expansão do sistema do capital, como também gerar e transmitir um quadro de valores que legitima os interesses dominantes, como se não pudesse haver nenhuma alternativa à gestão da sociedade, seja na forma "internalizada" (isto é, pelos indivíduos devidamente "educados" e aceitos) ou através de uma dominação estrutural e uma subordinação hierárquica e implacavelmente imposta. (MÉSZÁROS, 2008, p.35)

Para a expansão do sistema do capital, é necessário precarizar o trabalho, nesse caso, o trabalho docente e desvalorizá-lo em todos os níveis de ensino. Sobre isso, Souza (2012), afirma que temos uma formação docente de caráter pouco reflexiva e identidade profissional vacilante, somados às mazelas impostas à profissão docente: baixos salários, péssimas condições de trabalho, jornada de trabalho extensa, entre outras. Nesse contexto, ainda, Souza (2012) argumenta que [...], o professor precisa ter conhecimento do seu papel no processo de ensino-aprendizagem, particularmente, aquele que lida com os sujeitos do campo excluídos de qualquer possibilidade de uma educação voltada para seu modo de vida.

Nesse contexto, a Geografia, como componente curricular no processo de ensinoaprendizagem, tem subsidio suficiente para trabalhar, em sala de aula, a identidade territorial camponesa e a sua valorização, seja em uma escola localizada no campo ou em espaços urbanos. Com isso, paralelamente, Souza (2012) pontua que existem dois elementos que se destacam na Geografia Acadêmica, que podem contribuir na práxis da Geografia escolar e que buscam valorizar a identidade camponesa, sendo elas as escalas de análises e a ruptura com dualidades, que ajudarão na compreensão do espaço, na leitura do território e uma análise totalizante que inclua campo e cidade, agrário e agrícola [...].

Sendo assim, para diagnosticar-se como se encontrava a práxis dos docentes da educação básica em sala de aula frente ao entendimento de camponês, realizou-se uma entrevista com três professoras da rede Estadual e Municipal de Ensino do Munícipio de Petrolina- PE; sendo que uma professora exerce à docência na Escola Estadual Joaquim André Cavalcante (professora A), a outra na escola na Escola de Referência em Ensino Médio Clementino Coelho (professora B); e na Escola Municipal José Cicero de Amorim e na Escola Estadual Malaquias Mendes (professora C), também como um bom requisito para a análise do 
Ensino no Município foi entrevistada a Formadora ${ }^{1}$ de professores de Geografia da rede municipal de Petrolina (professora D).

Solicitou-se das entrevistadas que conceituassem o ser camponês, e elas responderam: "Pessoa que vive e sobrevive do campo". (Professora A- Informação escrita Entrevista 1) ${ }^{2}$. "Uma classe de trabalhador que vive do fruto do seu trabalho". (Professora C Informação escrita - Entrevista 1)

Como alguém que tira da terra sua sobrevivência. Assim, o camponês seria tanto para trabalhador assalariados sem terra como o agricultor de uma forma geral. Sociologicamente falando em camponês é quem vive estritamente da terra em uma produção familiar numa economia de subsistência. (Professora B - Informação escrita - Entrevista 1)

Como sujeito que trabalha e vive no campo e que dela tira seu sustento. Isso lhe gera um profundo laço com a terra, vínculos afetivos do seu meio de trabalho. (Professora D - Informação escrita - Entrevista 1)

Percebe-se, na fala das professoras, que o conceito de camponês ora se aproxima, ora se distancia do que é utilizado neste trabalho, tendo como base a definição de Shanin (2008), um sujeito que tem um modo de vida, constituindo-se classe ou não a partir de sua relação com a terra.

Conceituar o camponês é algo que exige uma análise complexa, pois não se pode tratar o conceito de camponês com modelos estabelecidos, pois, como afirma Shanin (2008):

[...] quando nós comparamos os modelos com a realidade, esta última é sempre mais complexas do que os modelos, e mais difícil de aprender devidamente. Isso não significa que modelos são inúteis. Mas, tratar modelos como se fosse a realidade é

${ }^{1}$ Baseando-se em três pilares educacionais, os professores formadores da Secretaria de Educação do município de Petrolina realizam atividades que vão de formações continuadas, acompanhamento pedagógico do educador, até o desenvolvimento de projetos que auxiliem os docentes de sala de aula no processo de ensino do estudante.

Disponível em: http://www.petrolina.pe.gov.br/petrolina2015/noticias.php?id=9794 Acesso em: 18 junho 2016.

${ }^{2}$ Entrevistas 1 - concedida por professores em [Jun/2016]. Entrevistador: Celmara Coelho. Petrolina, 2016. 
inútil e perigoso. Modelos são modelos e é importante que isso seja destacado para que possamos notar a diferença existente entre o conceito e a realidade, caso contrário, perderemos nossa capacidade de entender a realidade. (SHANIN, 2008. p.34)

Evidenciam-se, também, uns termos contraditórios na denominação da professora B, que faz uma mistura de agricultura camponesa e agricultura familiar, englobando o significado para todo sujeito que exerce atividade agrícola. Nesse contexto, Conceição (1991) ressalta que a palavra camponesa, ao ser aplicada em função da localidade, do tipo de atividade agrícola, fica limitada a sua relação etnológica, deixando em aberto à categoria ao ser definido o conceito de camponês.

Quanto à existência ou não do conceito de camponês nos livros didáticos, as professoras explanaram que: "Quase não aparece, e quando aparece menciona que é aquele que vive no campo". (Professora A - Informação escrita - Entrevista 1). "Como uma classe formada de trabalhadores que embora não seja escravos mas jamais podem abandonar seus lotes de terras". (Professora C - Informação escrita - Entrevista 1)

De forma genérica como alguém que tem sua sobrevivência tirada da terra. Foca-se apenas nas decisões de conceitos relacionados à agricultura, principalmente, sem se aprofundar como terra é apropriada e os conflitos gerados a partir dessa apropriação. (Professora B - Informação escrita - Entrevista 1)

Na maioria dos livros didáticos vê-se que o conceito de camponês é o mesmo de agricultor. Não há diferenciação. Outros dizem que o termo camponês é ultrapassado. (Professora D - Informação escrita - Entrevista 1)

A importância de entender o conceito de camponês, para Marques (2008), permite:

Apreender a complexidade do sujeito histórico que designa, diferentemente do que ocorre com outros conceitos como os de pequena produção e agricultura familiar. Trata-se de um conceito que possui uma história significativa no interior das ciências sociais e que tem se relacionado às disputas políticas e teóricas travadas em torno da interpretação da questão agrária brasileira e das direções tomadas pelo desenvolvimento capitalista no campo. (MARQUES, 2008, p.58)

E sobre a relevância de estudar o campo nos livros didáticos, as professoras afirmam que: "É a base de qualquer sociedade mais justa." (Professora A - Informação escrita - 
Entrevista 1). "Por que mostra a realidade de muitos que sofrem para conseguir sua sobrevivência. (Professora C -- Informação escrita - Entrevista 1)

A escola é um dos locais da sociedade que contribui para a construção do conhecimento e deve existir nos livros didáticos uma visão crítica das relações que se processam no campo como os movimentos sociais, reforma agrária e latifúndio. (Professora B - Informação escrita - Entrevista 1)

É do campo que surgem nossas origens históricas. É no campo que vê-se a luta por justiça e igualdade a partir da divisão da terra. O conteúdo deve sim ser trabalhado em nossas escolas. (Professora D- Informação escrita - Entrevista 1)

As docentes entram em acordo no sentido de que o camponês é importante para a sociedade: "É de grande importância, essencial, já que precisamos deles para nossa sobrevivência, porém na prática, nenhuma". (Professora A - Informação escrita - Entrevista 1). "É considerado a classe fundamental para desenvolvimento da agricultura, representa o meio rural". (Professora C - Informação escrita - Entrevista 1)

Como uma das bases para a produção de alimentos, tanto para subsistência como para o mercado interno, dando segurança alimentar para qualquer país. (Professora B - Informação escrita - Entrevista 1)

Importância enorme. O nosso sustento alimentar vêm do campesinato. Contudo, esse sujeito não é reconhecido como deveria. (Professora D - Informação escrita Entrevista 1)

Entre estudar o campo e a importância camponesa, há uma contradição. A professora B relata a criticidade da questão agrária; contudo, afirma ser o camponês um sujeito que deve produzir para o mercado, destacando a segurança alimentar - conceito criado pelos organismos multilaterais para aumentar a produção de alimento com base em aumento de tecnologia e uso de agrotóxicos. Ressalta-se que é um conceito utilizado pelo Estado para distanciar da soberania alimentar defendida pelos movimentos sociais como condição de existência. A professora C relata o campo como meio rural - "meio" é uma palavra que, na ciência geográfica significa nada, lugar da não produção, ou seja, subsistência ou sub existência.

Mas, a Geografia escolar, por meio do comprometimento do professor em sala de aula, pode contribuir para o resgate do sujeito camponês, mesmo que os caminhos da educação no país sejam guiados para a produção, acumulação e desvalorização do sujeito, particularmente, daqueles que vivem no/do campo. 
Ainda, as professoras A e D destacam as dificuldades para trabalhar o campo em sala de aula, afirmando: "É difícil, devido a muitos conteúdos cobrados e pouco material disponível”. (Professora A - Informação escrita - Entrevista 1).

É complicado, porque aparece em partes essa dificuldade no conteúdo "movimento sem terra", pois, há dois lados da questão e por isso ideias que apoiam ou criticam o movimento. (Professora D - Informação escrita - Entrevista 1)

A docente A deixa transparecer que o material didático é superior à capacidade crítica do docente. Contudo, as demais expressam não terem dificuldades em trabalhar com conteúdos relativos ao campo em sala de aula e elucidam: "Porque há muitos alunos do campo aí facilita o trabalho". (Professora C - Informação escrita - Entrevista 1)

Existe inúmeras fontes de pesquisa que contribuem para o debate de forma crítica sobre as relações capitalistas que se desenvolvem no campo, os conflitos e os movimentos de resistências da sociedade ao que está estabelecido pelo poder. (Professora B - Informação escrita - Entrevista 1)

Em relação aos conteúdos referentes ao campesinato serem abordados em escolas urbanas, as entrevistadas responderam: "Acredito que trabalhar este conceito em uma escola rural seria mais fácil, já que se pode usar como exemplo a vida deles. (Professora A Informação escrita - Entrevista 1). "Os alunos do meio rural têm mais facilidade em entender, por conhecer o meio em que vive". (Professora C - Informação escrita - Entrevista 1)

É importante, porque a maioria das vezes o estudante não tem ideia do que acontece nas áreas rurais e não tem a oportunidade de vivencia-la na prática. (Professora B Informação escrita - Entrevista 1)

O espaço urbano há uma distância da realidade estudada e por isso é preciso maiores "artimanhas" do professor para aproximar o conteúdo da realidade do aluno. (Professora D - Informação escrita - Entrevista 1)

O relato das professoras não considera que há uma relação campo/cidade e que eles não se separam, mas, se completam. Ainda, não consideram uma ferramenta indispensável da Geografia - trabalho de campo, como caminho para uma aprendizagem significativa. Para Souza Neto (2008), a Geografia é antes uma ciência de muitas trilhas, com laboratórios a céu 
aberto, com leituras que usam as asas do livro para voar sobre o mundo, com desdobramentos profissionais que vão da arte ao planejamento. (SOUZA NETO, 2008, p.100)

Para trabalhar assuntos relativos ao campesinato, sua valorização com o território nas escolas, no componente curricular Geografia em particular, é necessária a participação do professor e de toda a comunidade para assim romper com a mesmice, que é comum no espaço escolar. Callai (2001) explica que é preciso nas escolas uma prática

[...] que seja aberta à possibilidade de questionar o que se faz, de incorporar de fato os interesses dos alunos, e de ser capaz de produzir a capacidade de pensar, agindo com criatividade e com autoria de seu pensamento. Ao discutir esta postura, questionam-se as propostas prontas, implantadas nas escolas, até porque elas não têm conseguido entrar em definitivo na vida das escolas. (CALLAI, 2001. p. 134)

Descortinar as armadilhas da questão agrária deve ser um compromisso de curso de Geografia, da Geografia Agrária, para que os alunos do curso (futuros professores) trabalhem, nas escolas de Educação Básica, o conceito com eficiência sem contradição entre essência e aparência.

\section{O conceito de camponês pela análise dos estudantes da rede municipal e estadual}

Cotidianamente, ouve-se falar de camponês como um sujeito atrasado e que mora no campo por falta de oportunidade. Dentro dessa perspectiva, procurou-se verificar como os estudantes, no espaço urbano e rural, conceituam esse sujeito.

Para isso, entrevistaram-se alunos de séries referentes aos livros que foram avaliados para este trabalho; contudo, no artigo, optou-se pelas séries do $9^{\circ}$ ano do Ensino Fundamental II e do $3^{\circ}$ ano do Ensino Médio, tidas como séries de transição, tanto no espaço urbano como no espaço rural, totalizando 142 alunos do $9^{\circ}$ ano distribuídos na Escola Municipal José Cícero de Amorim ${ }^{3}$ e na Escola Estadual Joaquim André Cavalcante ${ }^{4}$ e 78 alunos do $3^{\circ}$ ano

\footnotetext{
${ }^{3}$ Escola localizada no distrito de Rajada, zona rural do Município da Cidade de Petrolina-PE. Uma escolada rede municipal de ensino referente às séries do $6^{\circ}$ ano ao $9^{\circ}$ ano.

${ }^{4}$ Escola localizada no bairro José e Maria na cidade de Petrolina-PE e que faz parte da rede Estadual de ensino do Estado de Pernambuco do $6^{\circ}$ ano ao $9^{\circ}$ ano.
} 
do Ensino Médio distribuídos nas escolas Malaquias Mendes da Silva ${ }^{5}$ e na Escola de Referência em Ensino Médio Clementino Coelho ${ }^{6}$.

FOTO 01: Aplicação de Questionário na Escola Estadual Joaquim André Cavalcante

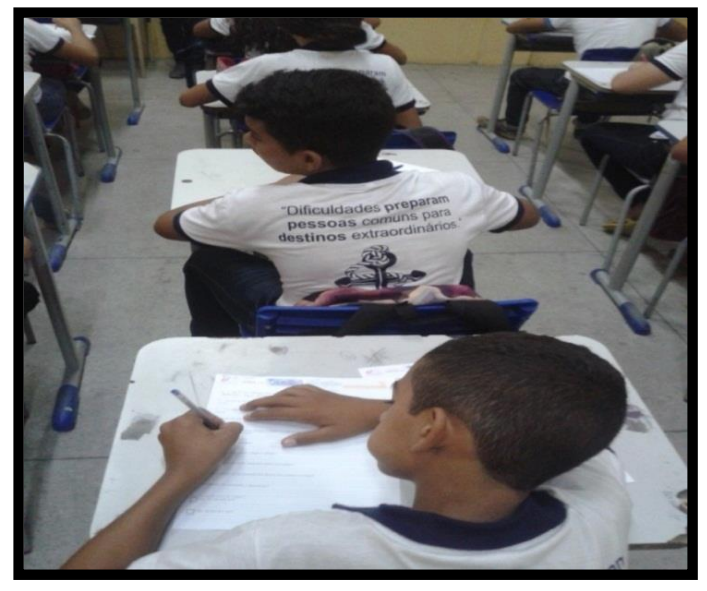

Fonte: AMORIM, Celmara Coelho de. 2016

\section{FOTO 02: Aplicação De Questionário Na Escola Municipal José Cícero De Amorim}

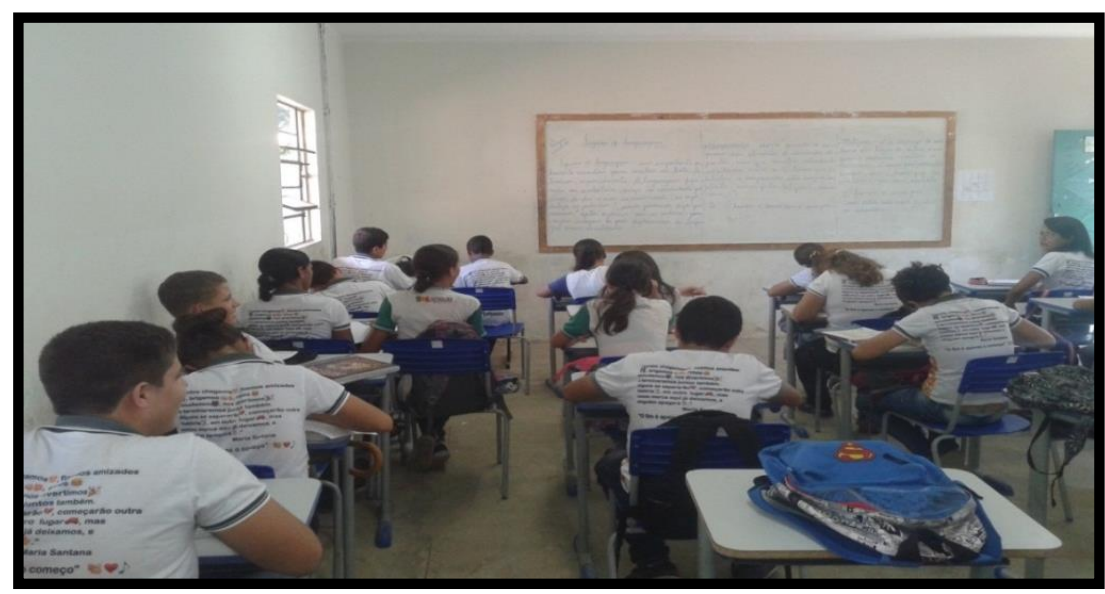

Foto: AMORIM, Celmara Coelho de. 2016

${ }^{5}$ Escola localizada no distrito de Rajada, zona rural do município da Cidade de Petrolina-PE, também uma escola da rede Estadual de ensino, atendendo ao publico de alunos do $1^{\circ}$ ano do Ensino Médio ao $3^{\circ}$ ano do Ensino Médio.

${ }^{6}$ Escola localizada Avenida da Integração s/n - Jardim Maravilha, Petrolina / PE, que integra a rede Estadual de ensino Integral e de referencia, com as séries do $1^{\circ}$ ano ao $3^{\circ}$ ano do Ensino Médio. 
A princípio, verificou-se a relação dos discentes com o campo, constatando que, na escola José Cícero de Amorim, 94\% dos alunos são filhos de sujeitos, que são ou foram camponeses. Já na escola Joaquim André Cavalcante, uma unidade de ensino urbana, 40\% dos alunos possuem alguma relação direta ou indireta com o campo. Na análise referente às respostas dos estudantes do $3^{\circ}$ ano, averiguou-se que, na Escola de Referência em Ensino Médio Clementino Coelho, 75\% dos alunos não possuem vínculo familiar com o campo, enquanto que, na escola Malaquias Mendes da Silva, 98\% dos estudantes possuem vínculo direto com o campo, sendo filhos de camponeses.

Ao questionar os discentes a respeito do conceito de camponês, eles responderam:

FIGURA 1: Conceito dos Estudantes

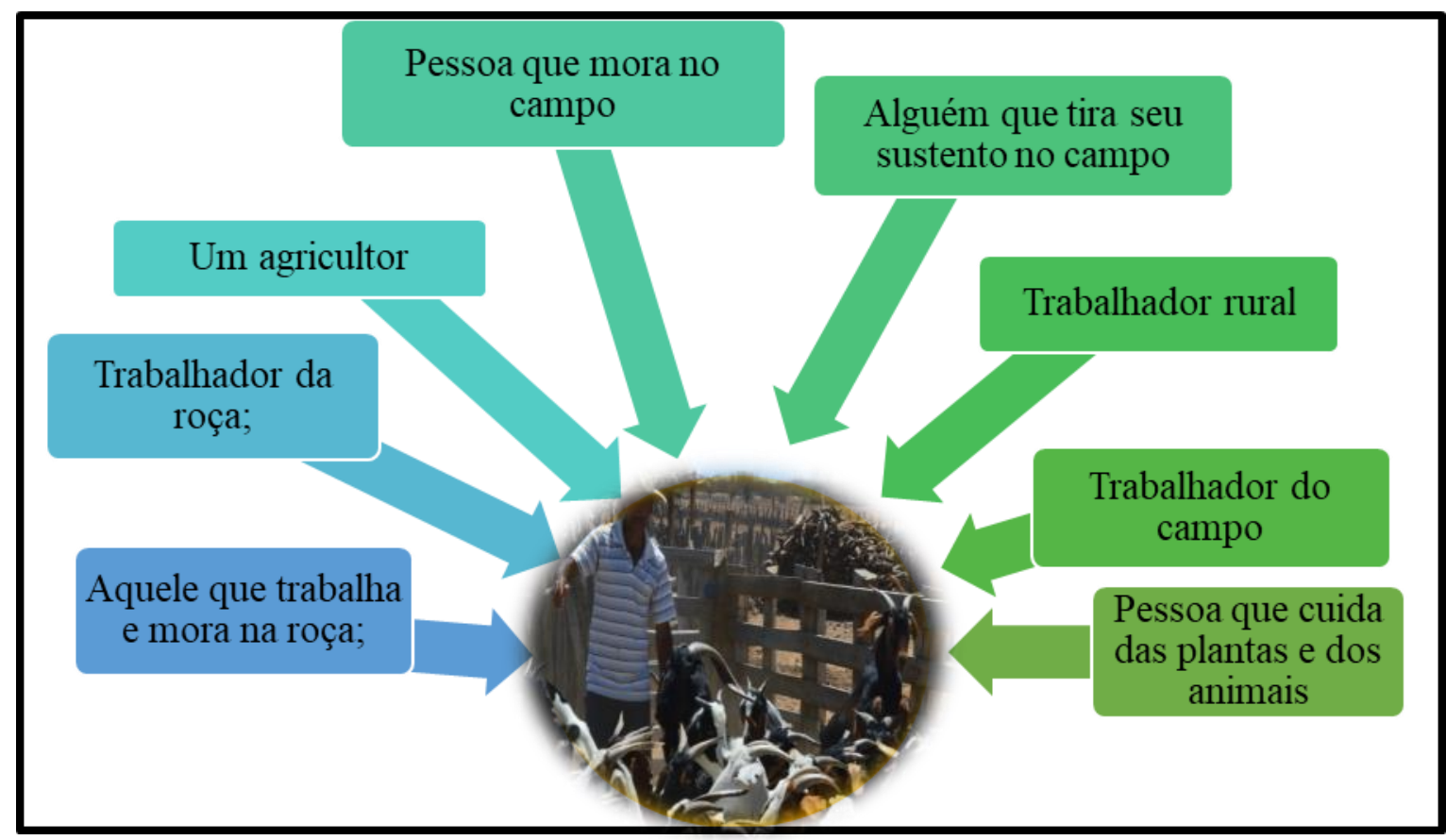

Fonte: Pesquisa de campo 2016.

Elaboração: AMORIM, Celmara Coelho de. 2016

No quadro, constata-se que as respostas dos alunos se distanciam daquilo que é atribuído por Shanin (2008) enquanto sujeito que um tem modo de vida diferenciado do urbano e pode tornar-se classe social. 
As análises deles não partem do campo enquanto condição de vida dos sujeitos, mas de um espaço atrasado, associando e à esfera econômica ou bens materiais e, a partir daí, conceituam como pessoas que fazem a agricultura, que moram no campo, que trabalham na roça, portanto, distantes do urbano. Notam-se conceitos que são oriundos ora da vivência dos/das professores/as, ora dos livros didáticos via imagens ou textos simples. E diante dessa premissa, vislumbra-se uma parcialidade dicotômica da realidade do camponês, pois a economia é apenas uma esfera da sociedade; não é a totalidade.

Foi interrogado aos alunos a respeito da diferença de campo e cidade, e as respostas contribuíram para a naturalização do campo como atraso e a cidade como ápice do desenvolvimento. "Nas cidades, a chance de emprego é maior e melhor, no campo só produção de alimento". (Informação escrita - Entrevista 2) ${ }^{7}$. "O campo é chato, e a cidade é ótima". (Informação escrita - Entrevista 2). "Pois a cidade é mais industrializada e tecnológica". (Informação escrita - Entrevista 2). "Campo é onde algumas pessoas da roça moram, e cidade é onde os mais ricos moram”. (Informação escrita - Entrevista 2). "A cidade tem vários meios modernos, e o campo é bem simples e não tem nada de atualidade. (Informação escrita - Entrevista 2). "No campo, é realizado o trabalho rural, pescar, cuidar dos animais; na cidade, são pessoas formadas como advogados e engenheiro". (Informação escrita - Entrevista 2).

Em determinados momentos, o conceito campo e cidade aparecia como paisagem natural e não como um território de vida, de trabalho. Algumas respostas: "No campo tem mato e bichos e a cidade tem lojas e escolas e etc.". (Informação escrita - Entrevista 2). "O campo é verde com muita plantação, e a cidade tem carros e prédios”. (Informação escrita Entrevista 2). "A cidade só tem casas, prédios e muitas pessoas; no campo só têm fazendas, sítios, animais e rios.” (Informação escrita - Entrevista 2).

\footnotetext{
${ }^{7}$ Entrevistas 2 - concedida por Estudantes em [Jun/2016]. Entrevistador: Celmara Coelho. Petrolina, 2016.
} 
Verifica-se que os conteúdos relativos ao espaço rural não são trabalhados como um território de vida, mas do atraso e, por isso, justifica-se a apropriação do capital via latifundiários. Mesmo assim, o campesinato permanece, porque o campo é pertencimento. Marques (2008) analisa que:

Enquanto o campo brasileiro tiver a marca da extrema desigualdade social e a figura do latifúndio se mantiver no centro do poder político e econômico - esteja ele associado ou não ao capital industrial e financeiro -, o campesinato permanece como conceito-chave para decifrar os processos sociais e políticos que ocorrem neste espaço e suas contradições. (MARQUES, 2008. p. 58)

A ênfase ao campo como espaço atrasado veiculado aos meios de comunicação repercute na análise dos alunos no gráfico que segue:

GRÁFICO 01: A importância de viver ou não no campo por estudantes da escola Joaquim André Cavalcante Referente

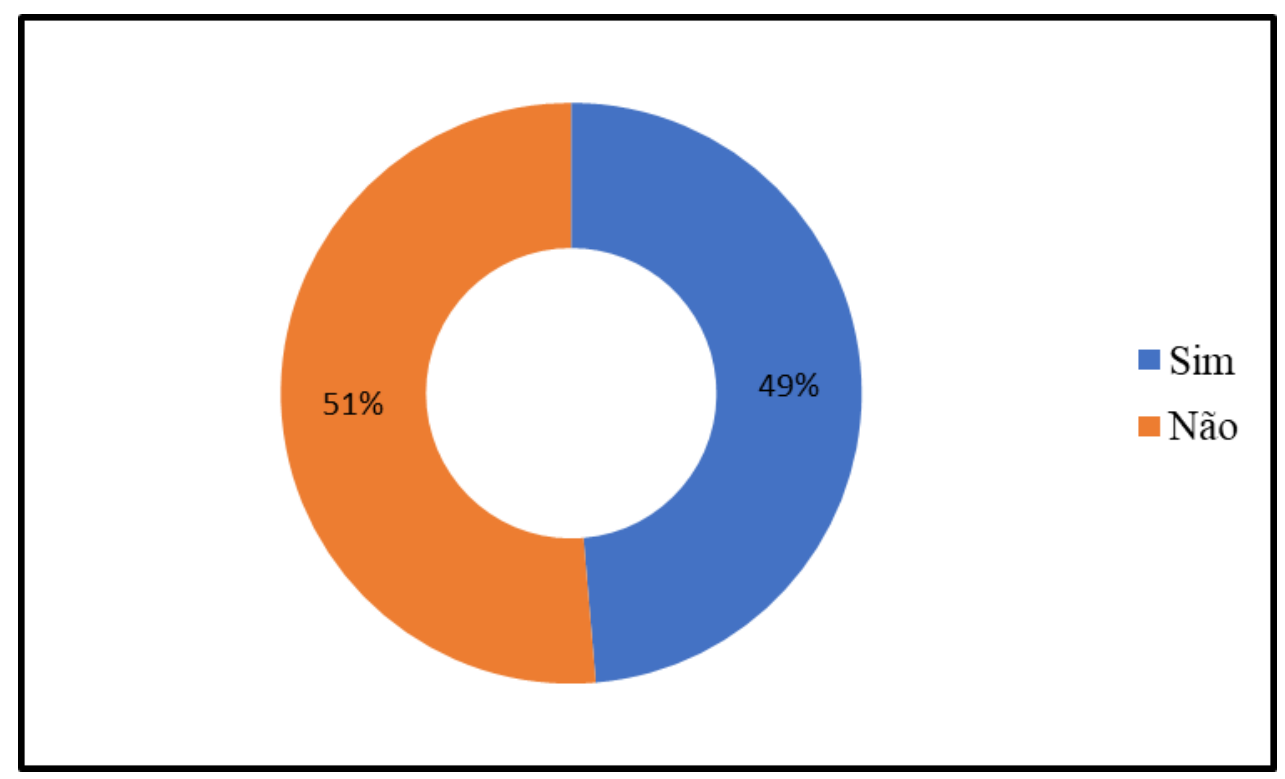

Fonte: Pesquisa de campo 2016

Elaboração: AMORIM, Celmara Coelho de. 2016

É importante mencionar que os livros didáticos utilizados nas escolas nem sempre apresentam o assunto sobre o campesinato, evidenciando nas escolas pesquisadas que para os alunos do $9^{\circ}$ ano: $61 \%$ dos alunos da escola Joaquim André Cavalcante confirmam já terem estudado, $31 \%$ deles acusam que não e $4 \%$ desses alunos não lembram se já estudaram ou 
não. Quantos aos alunos da escola José Cícero de Amorim, 63\% deles confirmam já ter estudado e $13 \%$ acusam que não e $24 \%$ não lembram se já estudaram ou não. Enquanto que, para os estudantes do Ensino Médio da Escola Malaquias Mendes da Silva, 100\% dos alunos afirmam já terem estudado sobre o campesinato e na Escola de Referência em ensino Médio Clementino Coelho, $94 \%$ dos alunos já estudaram o campo e 6\% desses afirmaram não ter estudado. Ratifica-se, portanto, a pouca ênfase ao espaço rural dada pelos docentes.

Mesmo que os meios de comunicações e as escolas não deem a importância devida ao campo, os alunos consideram importante estudar o assunto em sala de aula, conforme o gráfico a seguir.

Gráfico 02: A importância de estudar o espaço agrário nas escolas

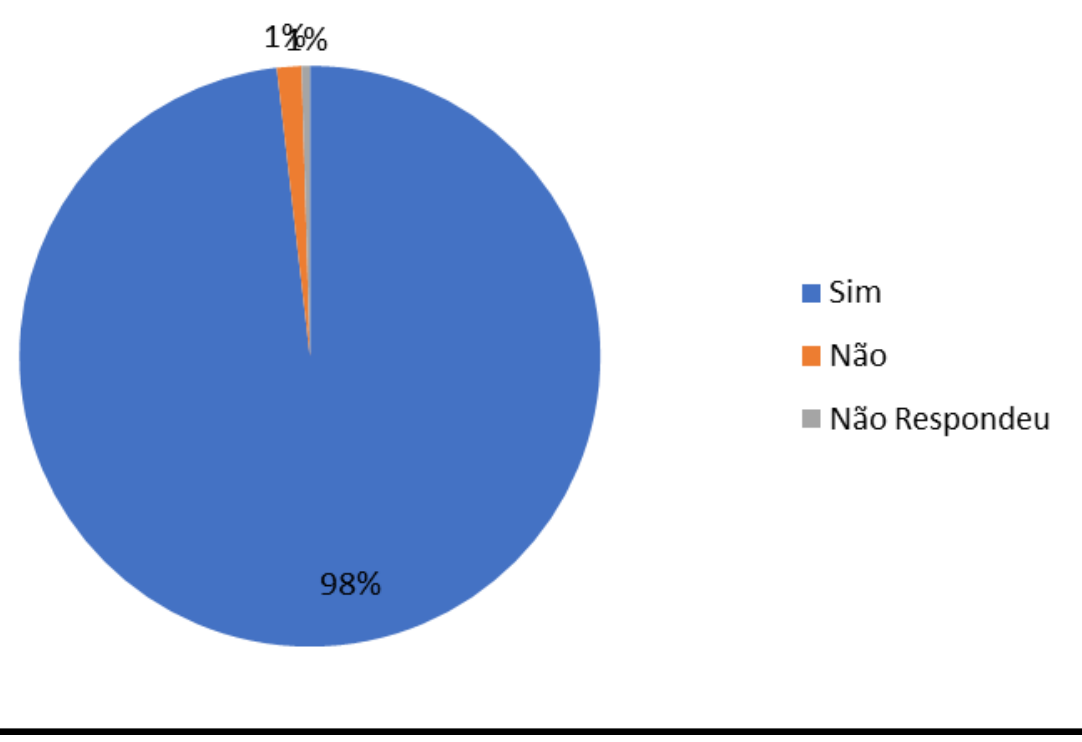

Fonte: Pesquisa de campo 2016

Elaboração: AMORIM, Celmara Coelho de. 2016

Os alunos da Escola Joaquim André Cavalcante e da Escola de Referência em ensino Médio Clementino Coelho, duas escolas situadas no espaço urbano, percebem a importância da existência da agricultura familiar e não da agricultura camponesa, o que pode ser visto nas falas e no desenho que seguem: "Se não fossem os camponeses não teríamos frutas e verduras". (Informação escrita - Entrevista 2). "Porque eles cuidam das frutas". (Informação escrita - Entrevista 2). "Porque eles cultivam as frutas e mandam para a cidade". (Informação escrita - Entrevista 2). "Eles que ajudam a reproduzir as frutas, os trigos". (Informação escrita 
- Entrevista 2). "Porque a maioria trabalha em roça de uva, manga e é através da colheita que as pessoas compram as frutas”. (Informação escrita - Entrevista 2).

Figura 02: A realidade do campo pelos alunos da Escola Malaquias Mendes da Silva

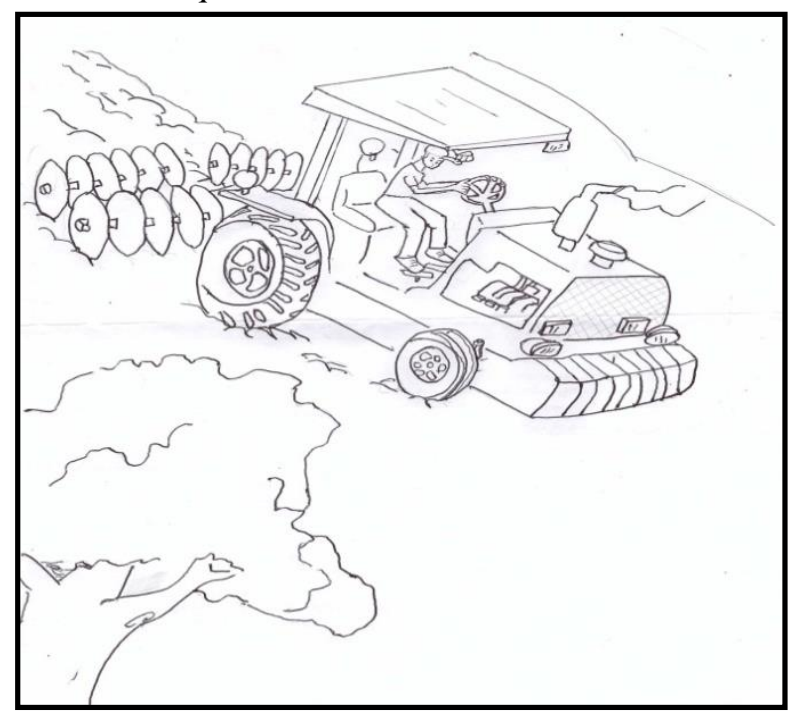

Fonte: Pesquisa de campo 2016, na Escola Malaquias Mendes da Silva

Elaboração: AMORIM, Celmara Coelho de. 2016

Fonte: pesquisa de campo/2016
Figura 03: A realidade do campo pelos alunos da Escola Joaquim André Cavalcante

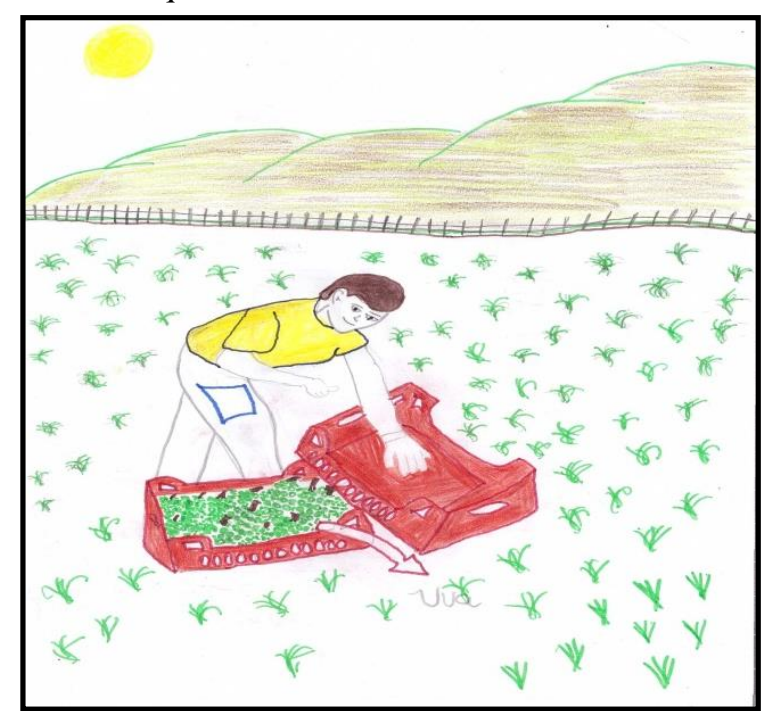

Fonte: Pesquisa de campo 2016, na Escola Joaquim André Cavalcante

Elaboração: AMORIM, Celmara Coelho de. 2016

Fonte: pesquisa de campo/2016

Nas ilustrações, vê-se claramente como o estudante percebe a agricultura - tecnologia e plantio de uva para atender ao mercado interno e externo. Os mesmos não estão errados em terem essa concepção sobre o camponês na nossa sociedade, porque é essa que lhe é apresentada diariamente. Contudo, desconhece a essência dessa realidade, uma vez que a tecnologia utilizada pelo agronegócio exige uso de agrotóxicos, ao passo que expropria os trabalhadores de sua terra para o assalariamento nas grandes empresas. Portanto, não há incentivo de gêneros alimentícios necessários à reprodução humana, somente o cultivo com valor de mercadoria. 


\section{O conceito de camponês pelo camponês}

A forma como o camponês se auto define é representada por palavras que expressam e referenciam o sujeito que vive no campo, mas que, na sua essência, são expressões com certa contradição, como: agricultor, produtor rural, lavrador, trabalhador rural, denominações essas mais usadas pelos camponeses para se auto definirem.

Em entrevista com um camponês, perguntou-se a ele: Como é conhecido pelo seu trabalho na roça. Rapidamente, ele respondeu: “Agricultor". ${ }^{8}$ (Informação escrita - Entrevista $3)$.

Segundo Conceição (1991), na palavra agricultor, há uma conotação diferenciada das outras denominações. Embora possa ser um pequeno produtor, nela, está contida a concepção de melhoria de vida, aquele que produz excedente. Para esse sujeito, a palavra camponesa é estranha, remete a algo que, a princípio, desconhece, mas, ao mesmo tempo, para ele ser agricultor é: "trabalhar na terra para tirar o sustento da família". (Informação escrita Entrevista 3).

A resposta, portanto, liga-se ao que Caldart (2012) expressa: nas unidades de reprodução camponesa: a centralidade é a reprodução social dos seus trabalhadores diretos, que são os membros da família sem assalariamento e obtenção de lucro.

$\mathrm{Na}$ oportunidade da entrevista, foi questionado se ele tem vontade de sair da roça e exercer outro trabalho. Ele reage: Não! Por enquanto, é aqui na roça que quero ficar. (Informação escrita - Entrevista 3).

Sobre trabalhar na roça e seu horário, a explanação foi a seguinte:

Aqui na roça é assim, levanto $4 \mathrm{~h}, 5 \mathrm{~h}$ da madrugada, ai escurece até $7 \mathrm{~h}$ da noite, $12 \mathrm{~h}$ venho só pegar o feijão, deito uma horinha, ai volto novamente e tem dia que $12 \mathrm{~h}$ nem venho em casa. (Informação escrita - Entrevista 3).

Comprova-se, na fala, que, no campesinato, a carga horária de trabalho é ditada pelo camponês e também pelas características do ciclo da produção; seca ou inverno é o que o influencia para a execução das atividades no campo. Segundo Shanin (2008), o horário de trabalho é, parcialmente, uma questão de escolha, de cultura; diferentes culturas esperam que ajam de diferentes maneiras.

Em relação ao estudo do campo na escola, a camponesa se expressa assim: "É bom demais estudar o campo na escola, eu já estudei. Assim você tem conhecimento de como você vai lidar com as coisas da roça". (Informação escrita - Entrevista 3).

Com isso, ela mostra uma série de lições que, como afirma Shanin (2008), os camponeses podem ensinar uma variedade de coisas que não sabemos. E continua a explanar

\footnotetext{
${ }^{8}$ Entrevistas 3 - concedida por camponeses em [Julh/2016]. Entrevistador: Celmara Coelho. Petrolina, 2016.
} 
que, ainda, sabemos muito pouco sobre o campesinato. Assim, seguem as lições dadas pelo camponês:

1. Produção de alimento para o gado - a partir do mandacaru ${ }^{9}$, primeiro se queimam os espinhos e, depois, tritura-os na forrageira, transformando-os em um farelo, alimento esse feito em época de seca, como alternativa por não ter mais pastos verdes, mostrando, assim, as diversas formas de adaptar-se às situações de crise.

Foto 03: Alimentação para o gado

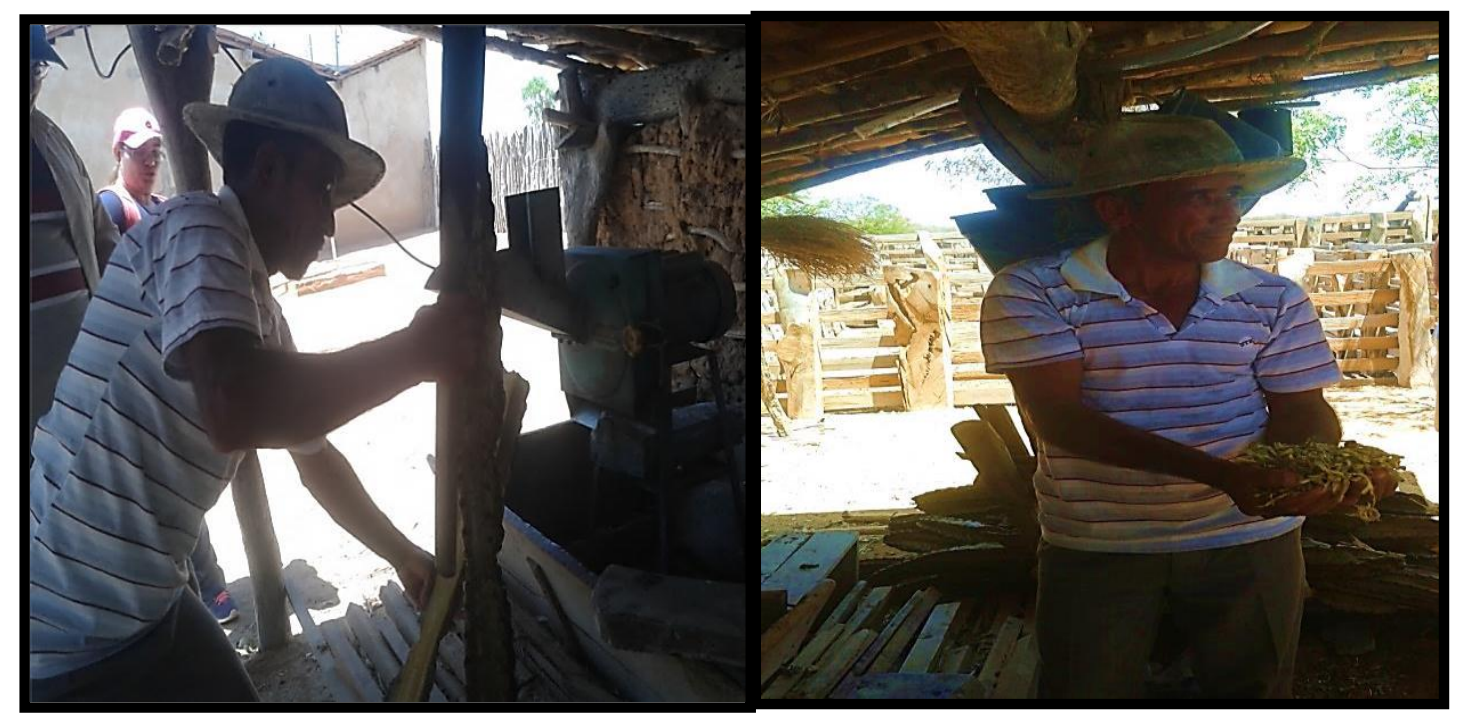

Fonte: Pesquisa de campo 2016

Elaboração: AMORIM, Celmara Coelho de. 2016

A respeito disso, Shanin (2008) pontua que as comunidades camponesas demonstram uma real habilidade para se ajustar a novas condições e também uma grande flexibilidade para encontrar novas formas de se adaptar e ganhar a vida.

2. Aproveitamento da água armazenada no subsolo - como uma das alternativas por não ter fornecimento de água e a construção de uma quadra usada para espalhar o farelo de mandioca para secar e depois armazenar. A pequena plantação de capim e hortaliças é

${ }^{9}$ De acordo com a definição do Dicionário Caldas Aulete, significa "cacto (Cereus jamacaru) nativo do Brasil, de porte arbóreo, ramificado, com flores grandes que se abrem à noite, típico da caatinga, onde serve de alimento ao gado, e também cultivado como ornamental e por propriedades terapêuticas". Disponível em: < http://www.infoescola.com/plantas/mandacaru/> Acesso em: 24 .06.2016. 
irrigada com água do poço; o capim é para a alimentação do gado, passando pelo processo de trituração na forrageira, e as hortaliças são para o consumo da família.

Foto 04: Aproveitamento de água

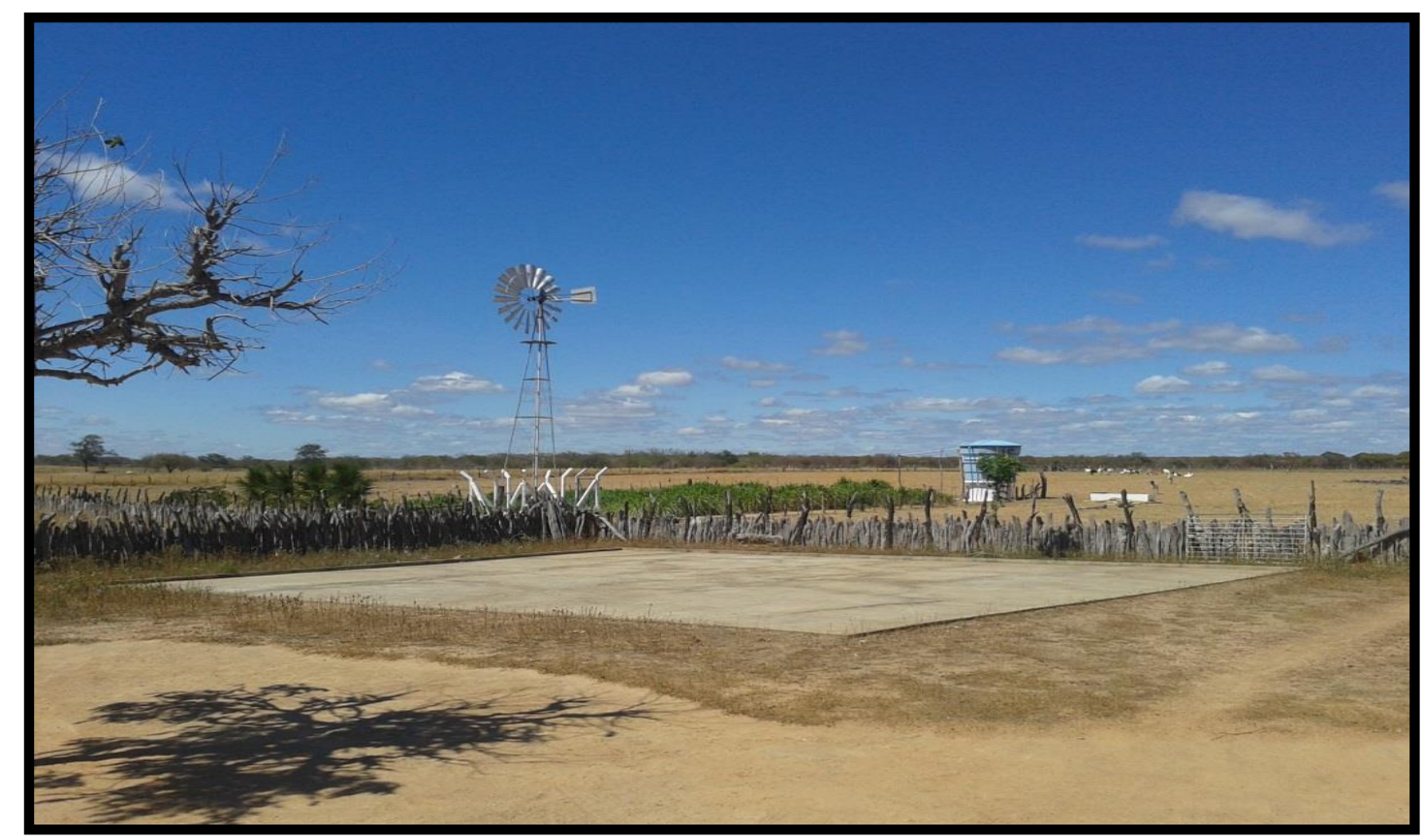

Fonte: Pesquisa de campo 2016

Elaboração: AMORIM, Celmara Coelho de. 2016

[...] a resposta do campesinato às situações de crise nas quais eles são submetidos é, sobretudo complexa e eles não ficam esperando que alguém traga a solução. As soluções encontradas para o problema de como permanecer camponês e assegurar a subsistência da família costumam ser muito flexíveis, inventivas e criativas. (SHANIN, 2008. p. 25)

3. Riqueza da caatinga - objetos para suprir algumas necessidades, na imagem 1 , uma vassoura de fabricação artesanal com plantas da caatinga, sem nenhum custo; a imagem 2 mostra o uso de garrafa pet para irrigar as plantas de porte médio; deposita-se água na garrafa, que tem um furo embaixo e, com isso, acontecerá o gotejamento e a planta ficará molhada por longo tempo; a imagem 3 apresenta um recipiente feito da umburana ${ }^{10}$ para colocar a ração dos animais. Shanin (2008) ressalta que os camponeses têm provado ser

${ }^{10}$ Umburana é uma planta de grande porte e bem aromática semelhante ao cumaru, que se dá mais em áreas tropicais do Brasil e partes Amazônicas. Disponível em: https://www.vegetall.com.br/umburana/ > Acesso em: 24.06. 2016. 
extremamente resilientes e criativos em situações de crise e não há uma forma simplista para descrever isso.

Foto 05: Utilidades da caatinga
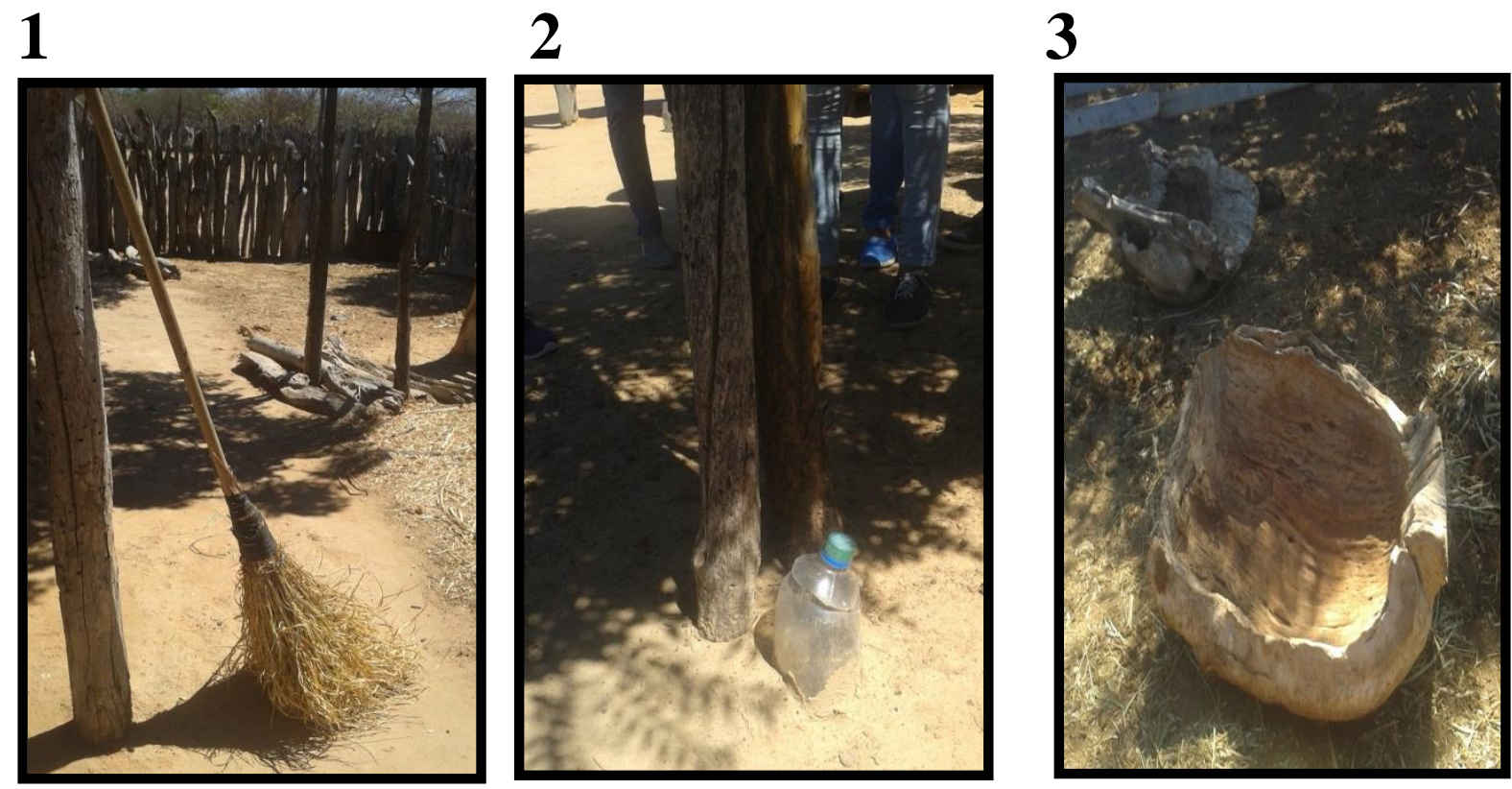

Fonte: Pesquisa de campo 2016

Elaboração: AMORIM, Celmara Coelho de. 2016

4. Recipientes para armazenar sementes - utilizados para o consumo diário da família, são guardadas de um ano a outro para o próximo plantio na época de inverno. Com isso, percebe-se que, na agricultura camponesa, o objetivo não é a reprodução e acumulação para o capital, mas a reprodução da família como um modo de vida.

A flexibilidade de adaptação, o objetivo de reproduzir o seu modo de vida e não o de acumulação, o apoio e a ajuda mútua encontrados nas famílias e fora das famílias em comunidades camponesas, bem como a multiplicidade de soluções encontradas para o problema de como ganhar a vida são qualidades encontradas em todos os camponeses que sobrevivem às crises. E, no centro dessas particularidades camponesas, está a natureza da economia familiar.

[...] O instrumento crucial para tudo isto, para a sobrevivência deles, é a economia familiar. A economia familiar é um elemento mais significativo para compreendermos quem o camponês é do que um modelo geral de campesinidade. (SHANIN, 2008. p. 25, 34) 
Foto 06: Armazenamento de alimentos

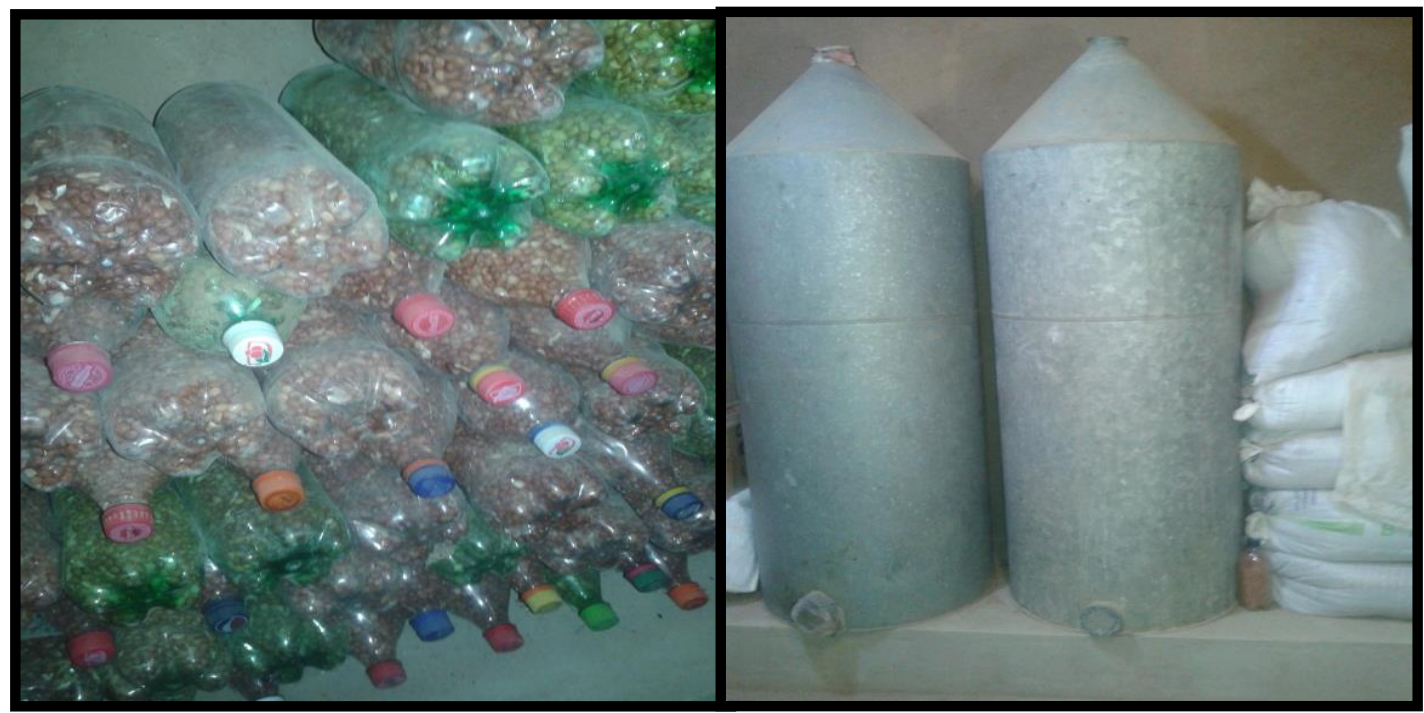

Fonte: Pesquisa de campo 2016

Elaboração: AMORIM, Celmara Coelho de. 2016

5. Trabalho criativo e flexivo - não existem os meios de subordinação; existe, no campesinato, uma diversidade de estratégias para a reprodução enquanto camponês.

[...] É verdade que, no mundo em que vivemos, os camponeses trabalham mais horas do que os operários [...]. Eles são, também, donos de seu próprio trabalho e assim são capazes de escolher sua própria maneira de descansar, o que é importante [...]. Essa é uma peculiaridade do trabalho camponês, é o trabalho de um homem que é dono do seu próprio trabalho e pode decidir como utilizá-lo. (SHANIN, 2008. p. 38)

Cada uma das lições evidencia que precisamos estudar os camponeses não só para ajudá-los, mas também para nos ajudar.

\section{Considerações finais}

O camponês brasileiro ao ser expropriado pela modernização da agricultura não tem representado uma ruptura total de seus vínculos com a terra. A maioria deles mantém alguma relação com o campo, seja ela mais próxima ou mais distante - relação direta de trabalho, vínculos familiares, relação de origem etc. Isso explica, em parte, a permanência, entre eles, de um conjunto de símbolos e valores que remetem a uma ordem moral ou lógica tradicional e a possibilidade de o acesso à terra se apresentar como uma alternativa para pobres do campo e 
da cidade que buscam assegurar a sua sobrevivência, mantendo a dignidade de trabalhador. (MARQUES, 2008).

Essa realidade não pode ser desconsiderada pelo professor quando inserir o conteúdo da questão agrária nas aulas de Geografia, pois cabe a ele como sujeito da práxis pedagógica escolar, em seu trabalho docente, estar atento a todos os elementos necessários para que o educando, efetivamente, aprenda e se desenvolva.

O docente, de modo algum, poderá obscurecer o fato de que o estudante é um sujeito ativo e que, para que ele aprenda, deverá criar oportunidades de aprendizagens ativas, de tal modo que desenvolva suas capacidades cognoscitivas assim como suas convicções afetivas, morais, sociais e políticas.

Ao planejar suas ações, deve considerar a não separação entre teoria e prática, isso porque, sendo teórica, não transforma a realidade - característica central da práxis. Portanto, para que a realidade seja transformada, a prática se faz necessária.

\section{REFERÊNCIAS}

CALDART. Roseli Salete et al. Agricultura camponesa, familiar, alternativas. In Dicionário da Educação do Campo. São Paulo: Expressão Popular, 2012.

CALlai, H. C. A Geografia e a escola: muda a geografia? Muda o ensino? In: Paradigmas da Geografia. Parte I. São Paulo: Editora da Associação dos Geógrafos Brasileiros, 2001 - Seção 2001.

CONCEIÇÃO, Alexandrina Luz. A Questão Camponesa: O Olhar Sob Signo Dialético. Aracaju: 1991.

MARQUES, Marta Inez Medeiros. A atualidade do uso do conceito de camponês. Presidente Prudente, 2008.

MÉSZÁROS, István. A educação para além do capital/ István Mézarós; [tradução Isa Tavares]. -2.ed. - São Paulo: Boitempo, 2008.

SHANIN, Teodor. Lições Camponesas. In: Campesinato e Território em Disputa org. Eliane Tomiasi Paulino, João Edimilson Frabini. $1^{\text {a }}$ Ed. São Paulo: Expressão Popular: UNESP: Programa de Pós Graduação em Geografia, 2008.

SOUSA NETO, Manoel Fernandes de. A Geografia Enquanto Ciência da Cabra Cega. Revista Paranaense de Geografia, Curitiba, v. 01, n. 01, p. 38-42, 1996. 
Aula de Geografia e algumas crônicas. $2^{\mathrm{a}}$ edição. Campina Grande: Bagagem, 2008.

SOUZA, Francilane Eulália de. O papel da geografia escolar para o fortalecimento da identidade territorial camponesa. In. As "geografias" das escolas no campo do município de Goiás: instrumento para a valorização do território do camponês? São Paulo, 2012. 